\title{
The response of serum leptin, cortisol and zinc concentrations to concurrent training
}

\author{
Guilherme Rosa, ${ }^{1}$ Estélio H.M. Dantas, ${ }^{1}$ Danielli Braga de Mello ${ }^{1,2}$ \\ ${ }^{1}$ Laboratory of Human Kinetics Science of the Federal University of Rio de Janeiro State - LABIMH/UNIRIO, ${ }^{2}$ Brazilian \\ Army Physical Education School (EsEFEx), Rio de Janeiro, Brazil
}

\begin{abstract}
OBJECTIVE: To investigate the effects of concurrent training (CT) on serum leptin, cortisol and zinc concentrations in physically active adults. DESIGN: Ten subjects aged (27.1 44.8 years, BMI $25.49 \pm 2.65$ ) were recruited to participate in three sessions: control session (CS), concurrent training 1 (CT1) and concurrent training 2 (CT2) sessions with five days of resting between them. In each session blood samples for leptin, cortisol and zinc determination were collected. CT1 session included indoor cycling class followed by strength training. CT2 session included strength training, followed by indoor cycling class. In CS there were no exercises. The Shapiro-Wilk test, repeated ANOVA test and Tukey Post-Hoc test were used. RESULTS: There was a reduction in leptin levels after CT1 $(\Delta \%=-16.04 ; p=0.05)$ and $\mathrm{CT} 2(\Delta \%=-8.54 ; p=$ 0.02). Cortisol also showed a reduction after CT1 $(\Delta \%=-26.32 ; p=0.02)$ and CT2 $(\Delta \%=$ $-33.57 ; p=0.05$ ), whereas zinc did not show any significant alterations after any of the training sessions. There was also significant difference for the leptin and cortisol values between CT1 and CT2. CONCLUSIONS: CT promoted reduction in serum leptin and cortisol levels independently of the training order, while no significant changes in zinc concentrations were observed.
\end{abstract}

Key words: Aerobic exercise, Cortisol, Cytokines, Hormones, Leptin, Physical exercise, Strength exercise, Stress response, Zinc

\section{INTRODUCTION}

Aerobic and strength exercise performed in the same training session (concurrent training) ${ }^{1}$ is very frequently used because of its beneficial effects. ${ }^{2} \mathrm{Al}-$ though some studies ${ }^{3-11}$ have investigated the effects

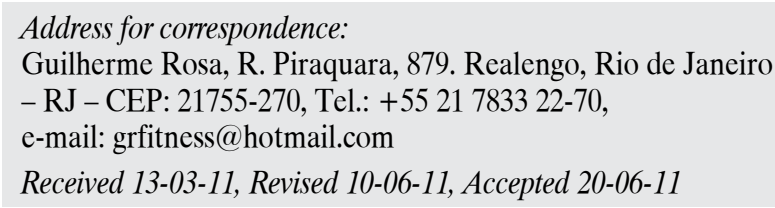

of physical exercise on leptin, cortisol and zinc levels, pertinent investigations using concurrent training as intervention protocol are rare.

Leptin is considered one of the most important hormones secreted by adipose tissue ${ }^{12}$ as it has been shown to be vital not only in the regulation of appetite and energy balance but also of neuroendocrine and immune functions. ${ }^{13}$ Moreover, several factors exert a direct influence on leptin levels, such as glucocorticoids, physical exercise ${ }^{14,15}$ and zinc. ${ }^{16-18}$ 
Cortisol is a glucocorticoid secreted by the adrenal cortex and among other functions, increases glyconeogenesis and promotes fat mobilization and utilization. ${ }^{19,20}$

Zinc also plays an important role in appetite regulation and may thus be expected to act as a mediator of leptin effects. ${ }^{21}$ Studies ${ }^{17,22,23}$ have shown low leptin levels in states of zinc deficiency. Furthermore, zinc supplementation seems to increase circulating leptin levels, ${ }^{22,24}$ thus showing a connection between zinc and leptin.

Rosa et $\mathrm{al}^{15}$ have shown a significant reduction in serum leptin after concurrent training, whereas Pérusse et $\mathrm{a}^{25}$ did not find any effect of acute and chronic physical exercise on plasma leptin levels.

Cadore et $\mathrm{a}^{26}$ did not observe significant changes in cortisol concentrations after an eight-week concurrent training period, while Rosa et $\mathrm{al}^{27}$ observed a significant decrease in serum cortisol levels after a single concurrent training session.

Taking into account the rarity of studies and the divergent literature data we investigated the effects of two distinct types of exercise as concurrent training on serum leptin, cortisol and zinc levels in physically active adults.

\section{SUBJECTS AND METHODOLOGY}

\section{Sample}

The study included ten male volunteers who had taken regular exercise for at least six months on at least three days per week and who did not have any apparent risk factors that could exclude their participation in the study in accordance with the American Heart Association Risk Stratification Criteria $-A H A .{ }^{28}$

The participants signed an Informed Consent document in accordance with the Helsinki Declaration..$^{29}$ The research project was approved by the $\mathrm{Hu}-$ man Subjects Research Ethics Committee at Castelo Branco University, under protocol no. 0189/2008.

Initially (phase 1), the study subjects underwent an anthropometric evaluation, including measurements of body weight, height and body mass index (BMI).

To evaluate body weight and height, a $150 \mathrm{~kg}$ capacity scale of $100 \mathrm{~g}$ accuracy was used in combination with a Filizola (Brazil) stadiometer. The aforementioned evaluations were based on the procedures recommended by the International Society for the Advancement of Kinanthropometry - ISAK. ${ }^{30}$ The BMI value was calculated by dividing body weight in $\mathrm{kg}$ by the square of the height in meters $\left(\mathrm{Kg} / \mathrm{m}^{2}\right){ }^{31}$

The participants completed the AHA/ACSM American College of Sports Medicine questionnaire which incorporated the risk stratification criteria for physical exercise participation. ${ }^{28}$

In the second phase of data collection, the One Repetition Maximum (1RM) test was performed ${ }^{32}$ aiming at the prescription and control of the intensity of the following exercises: supported rowing, leg press $45^{\circ}$, straight bench press, knee extensor, elbow extensor (HBM), knee flexor and elbow flexor (high-pulley).

Following these procedures, the subjects undertook an indoor cycle class using the OMNI scale of perceived effort to the cycling ${ }^{33}$ in order to familiarize themselves with this scale.

The subjects were enrolled in three different sessions: control session, concurrent training 1 (CT1) and concurrent training 2 (CT2). The interval between each session was five days during which normal routine of sleep, food intake and physical exercise was followed by all subjects.

\section{Control session}

Blood samples were collected from the subjects for the determination of baseline leptin, cortisol and zinc levels. Twelve hours of fast and a minimum of eight hours of sleep were recommended prior to sampling. None of the participants performed any kind of physical exercise on the day before this session.

The individuals then had a normal breakfast consisting of $200 \mathrm{ml}$ fat-free yogurt, two slices of light whole-wheat bread, $30 \mathrm{~g}$ of fresh cheese, $10 \mathrm{~g}$ of margarine and one medium-sized banana. Two hours after the first collection, new blood samples were collected to re-assess the leptin, cortisol and zinc levels. These procedures were undertaken between 06:30 and 08:30.

\section{CT1 session}

This session was carried out five days after the 
control session. In this session, the initial blood sample was obtained following the same procedure adopted in the control session. Forty minutes after breakfast, the group started a concurrent training session consisting of a 40-minute indoor cycling class using the continuous method with intensity between 5 and 7 of the OMNI scale of perceived effort to the cycling. ${ }^{33}$

Next, a strength training session was undertaken comprising three sets of repetitions performed until exhaustion for each tested exercise. The intensity was of $85 \% 1 \mathrm{RM}$ for all exercises and the rest interval between the sets was of 2-3 minutes.

After these procedures, the subjects were submitted to a new blood sample collection for analysis of the same variables.

\section{CT2 session}

In this session, the same procedure of the earlier sessions was followed, including effort intensity, while the concurrent training order was inverted: strength training session followed by an indoor cycling class. In this session, the strength training was preceded by a five-minute warm-up on the treadmill, with intensity ranging between $55-60 \%$ of reserve heart rate. ${ }^{28}$

During the control and CT sessions the subjects took only water ad libitum.

The blood samples were collected at the study site by qualified staff from the "Sérgio Franco Medicina Diagnostica" laboratory, Brazil, and transferred to the laboratory for analysis (radioimmunoassay analysis for plasma leptin, quimioluminescence immunoenzimatic assay for the cortisol and atomic absorption for the zinc determination).

All of the statistical procedures were processed with the Statistical Package for the Social Sciences software (SPSS 18.0, Chicago, USA). Descriptive statistics were used to establish the mean and standard deviation values. A repeated ANOVA test was applied for inferential analyses. The Shapiro-Wilk (SW) test and Tukey's Post-Hoc test were used. The Pearson's Correlation was used between the blood variables. A significance level of $p<0.05$ was applied.

\section{RESULTS}

In Table 1 the anthropometric characteristics of
Table 1. Anthropometric characteristics of the studied subjects

\begin{tabular}{lccc}
\hline & CS & CT1 & CT2 \\
\hline Body weight $(\mathrm{Kg})$ & $75.24 \pm 7.11$ & $74.72 \pm 6.67$ & $74.71 \pm 6.70$ \\
SW (p-value) & $\mathbf{0 . 0 9 7}$ & $\mathbf{0 . 1 8 9}$ & $\mathbf{0 . 1 2 7}$ \\
Height (m) & $1.72 \pm 0.03$ & $1.72 \pm 0.03$ & $1.72 \pm 0.03$ \\
SW (p-value) & $\mathbf{0 . 8 7 8}$ & $\mathbf{0 . 9 8 7}$ & $\mathbf{0 . 8 7 8}$ \\
BMI (kg/m $)$ & $25.49 \pm 2.65$ & $25.34 \pm 2.50$ & $25.29 \pm 2.54$ \\
SW (p-value) & $\mathbf{0 . 0 4 7}$ & $\mathbf{0 . 0 2 6}$ & $\mathbf{0 . 0 4 3}$ \\
\hline
\end{tabular}

CS: control session; CT1: concurrent training session 1; CT2: concurrent training session 2; BMI: body mass index; SW: Shapiro-Wilk normality test.

the individuals in the different sessions are presented.

The values of leptin, cortisol and zinc before (pre) and after (post) each session are depicted in Table 2.

A significant reduction $(\mathrm{p}<0.05)$ in leptin and cortisol levels was observed only after the CT1 and CT2 sessions, with significant difference $(p<0.05)$ between $\mathrm{CT} 1$ and $\mathrm{CT} 2$ for both variables.

No significant alterations in zinc values were observed after any of the sessions.

Table 3 presents the results of correlation $(r)$ between the blood variables at the pre and post sampling periods in all sessions.

A highly significant correlation ${ }^{34}$ was observed between leptin (pre) and cortisol (pre and post) at CS, and a moderate and significant correlation between leptin (post) and cortisol (pre and post) at CS. In the other sessions there was no significant correlation between the variables.

There was a highly significant correlation between leptin (pre) and zinc (pre), and moderate and significant correlation between leptin (post) and zinc (pre and post) at CS.

\section{DISCUSSION}

The data show that a single session of concurrent training induced a significant reduction in serum leptin levels independently of the order of the exercise component, this being in agreement with Kanaley, ${ }^{3}$ Landt, ${ }^{4}$ Keller $^{5}$ and Jürimäe ${ }^{6}$ who analyzed the response of leptin to aerobic and strength training separately performed. In the present study, there 
Table 2. Blood variables at the pre and post sampling in each session

\begin{tabular}{|c|c|c|c|c|c|c|}
\hline & \multicolumn{2}{|c|}{ Leptin (mcg/L) } & \multicolumn{2}{|c|}{ Cortisol (mcg/dl) } & \multicolumn{2}{|c|}{ Zinc (mcg/dl) } \\
\hline & PRE & POST & PRE & POST & PRE & POST \\
\hline $\mathrm{CS}$ & $5.12 \pm 1.01$ & $4.90 \pm 0.83$ & $13.94 \pm 3.29$ & $13.10 \pm 3.17$ & $801.00 \pm 87.49$ & $868.70 \pm 78.21$ \\
\hline CT1 & $9.97 \pm 6.12$ & $8.37 \pm 4.99 \S * *$ & $18.61 \pm 5.43$ & $13.71 \pm 4.87 \S^{* *}$ & $933.70 \pm 115.55$ & $978.30 \pm 213.78$ \\
\hline $\mathrm{CT} 2$ & $10.07 \pm 2.22$ & $9.21 \pm 2.21 \S^{* *}$ & $14.98 \pm 2.93$ & $9.95 \pm 2.26 \S^{* *}$ & $1302.10 \pm 81.50$ & $1264.30 \pm 86.76$ \\
\hline
\end{tabular}

CS: control session; CT1: concurrent training session 1; CT2: concurrent training session 2; for details see text. $\S$ : Significant difference $(\mathrm{p}<0.05)$ between groups; **: Significant difference $(\mathrm{p}<0.05)$ within groups.

To convert to SI units multiply by 27.6 for cortisol and by 0.153 for zinc.

Table 3. Correlation (r) between the variables at the pre and post sampling

\begin{tabular}{|c|c|c|c|c|c|c|}
\hline & \multicolumn{2}{|c|}{$\mathrm{CS}$} & \multicolumn{2}{|c|}{ CT1 } & \multicolumn{2}{|c|}{ CT2 } \\
\hline & $\begin{array}{c}\text { Leptin } \\
\text { (Pre) }\end{array}$ & $\begin{array}{c}\text { Leptin } \\
\text { (Post) }\end{array}$ & $\begin{array}{c}\text { Leptin } \\
\text { (Pre) }\end{array}$ & $\begin{array}{c}\text { Leptin } \\
\text { (Post) }\end{array}$ & $\begin{array}{c}\text { Leptin } \\
\text { (Pre) }\end{array}$ & $\begin{array}{c}\text { Leptin } \\
\text { (Post) }\end{array}$ \\
\hline Cortisol (Pre) & $-0.80 \S$ & $-0.62 \S$ & 0.50 & 0.00 & -0.53 & -0.51 \\
\hline Cortisol (Post) & $-0.81 \S$ & $-0.62 \S$ & 0.05 & 0.00 & -0.62 & -0.49 \\
\hline Zinc (Pre) & $-0.80 \S$ & $-0.67 \S$ & -0.07 & 0.08 & 0.01 & 0.25 \\
\hline Zinc (Post) & $-0.68 \S$ & $-0.61 \S$ & -0.18 & -0.01 & -0.47 & -0.17 \\
\hline
\end{tabular}

CS: Control session; CT1: concurrent training session 1; CT2: concurrent training session 2; §: Correlation between the variables $(\mathrm{p}<0.05)$.

was significant reduction in leptin levels after both CT1 and CT2.

Rosa et $\mathrm{a}^{15}$ used as intervention protocol a single session of concurrent training with modality characteristics, number of exercises, perform order, intensity and rest interval similar to those of the CT1 of the present study. Their results showed that, as in the present study, a single session of concurrent training induced a significant decrease in leptin levels.

The effects of concurrent training on leptin levels seem to depend on intensity. Thus Rosa et a ${ }^{35}$ observed that a training session with characteristics similar to those of the present study yielded the same results concerning effects on leptin concentration, whereas exercise performed with high intensity apparently promoted a negative energy balance, decreasing the leptin levels.

The length of the training session could constitute another factor affecting leptin levels. According to the review by Hulver, ${ }^{36}$ studies that investigated exercise sessions of one or more hour's duration, as the present one, are more representative with regard to changes in serum leptin concentrations. These findings raise speculation that exercise-associated reductions in leptin may also be due to alterations in nutrient availability or nutrient flux at the level of the adipocytes, the primary site of leptin production and secretion.

Despite the fact that leptin levels are directly related to the amount of body fat, Pérusse et $\mathrm{al}^{25} \mathrm{did}$ not detect any effects of acute and chronic physical exercise on plasma leptin levels, independently of the fat mass reduction of their sample after the exercise intervention.

Licínio $^{37}$ found that plasma leptin levels are pulsatile, with approximately 30 pulses in a 24 -hour period. According to Sinha, ${ }^{38}$ the concentrations reach peak levels between 11:00 and 13:00. Sample collections in the present investigation occurred before 11:00 and are therefore outside the time period mentioned.

In relation to cortisol, the data showed significant reduction in cortisol levels after the concurrent training independently of the order of the type of exercise. These data are similar to those of Kraemer. ${ }^{7}$

Rosa et $\mathrm{a}^{27}$ analyzed the acute effect of physical exercise on cortisol levels using a concurrent train- 
ing session with modality characteristics, volume and intensity of the CT1 session similar to those of the present study. Their results demonstrated that, as in the present study, the training protocol used induced a significant reduction in the subjects' cortisol levels.

In another study, Rosa et $\mathrm{al}^{39}$ examined the acute effect of distinct concurrent training sessions on cortisol levels. They used concurrent training sessions with the same exercise modes, volume and intensity as the CT1 and CT2 sessions of the present study. As observed here, their results show that the concurrent training protocol induced a significant reduction in cortisol levels, regardless of the sequence of concurrent training.

Horne et $\mathrm{al}^{40}$ examined the effect of a twelveweek protocol of strength, aerobic and concurrent training in cortisol levels. They showed an increase in cortisol levels in the concurrent training group and reduction only in the aerobic training group. These data are in disagreement with the present study, in which there was a reduction in cortisol levels after a single session of the concurrent training protocol. However, the length of the training protocols was different and this could explain the discrepancy in the results obtained.

Other authors have observed an increase in cortisol levels in their studies. According to Izquierdo, ${ }^{10}$ who used a high intensity strength training protocol, the magnitude of metabolic demand or the fatigue experienced during the strength exercise session influences the hormonal response patterns.

França ${ }^{9}$ also observed an increase in cortisol levels after a marathon, confirming that a marathon race may cause a marked physical stress. In this study, the intensity of the training applied was probably not enough to increase the cortisol levels.

According to Negrão et al, ${ }^{14}$ leptin levels can be influenced by glucocorticoids, such as cortisol, through stimulating the transcription of the leptin gene and also its production.

In the present study, leptin and cortisol levels showed significant reduction during CT1 and CT2 sessions; however, no significant correlation was disclosed between these variables after the training sessions. These data are in disagreement with the studies of Hafner, ${ }^{41}$ Licinio $^{37,42}$ and Bornstein ${ }^{43}$ who have reported that there is correlation between leptin and cortisol concentrations.

Apart from physical exercise, zinc can also exert an influence on serum leptin levels. ${ }^{11}$

According to Koury et al ${ }^{44}$ zinc changes after physical exercise are directly related to intensity and length of exercise. In our study no significant alterations were observed in the serum zinc levels.

Arikan et $\mathrm{a}^{45}$ examined the relation between leptin and zinc concentrations of athletes and sedentary people. They showed that leptin and zinc levels in the control group were significantly higher than those in the athletes and that leptin levels decreased significantly in parallel with zinc levels. In the present study, the leptin concentrations were significantly lower after the sessions CT1 and CT2, without significant changes in zinc concentrations. Leptin and zinc showed correlation only in the CS.

In the study of Chen et al, ${ }^{18}$ high leptin levels and low zinc levels in the experimental group were detected compared with the control group, demonstrating the existence of an inverse correlation between these variables.

Kwun et $\mathrm{al}^{22}$ investigated the relation between zinc deficiency and food intake by evaluating the expression of the leptin gene. There was a significant reduction in leptin gene expression in the group receiving a zinc deficient diet. In the present study the reduction in leptin levels was not followed by significant changes in zinc levels.

Gökbel et $\mathrm{a}^{46}$ investigated the possible changes in serum leptin concentration caused by acute exercise and the effects of zinc deficiency on these changes. The results showed that serum leptin levels significantly decrease after strenuous exercise. A further decrease in leptin levels was observed in those fed a zinc-deficient diet. Regarding the leptin concentrations, these data are similar to those of the present study, with a significant decrease in leptin levels after an exercise session.

Baltaci et $\mathrm{al}^{17}$ observed no increase in leptin levels induced by zinc deficiency. In their research, both leptin and zinc levels were lower in zinc deficient rats and higher in those receiving a normal diet and zinc supplementation. 
In another study, Baltaci et $\mathrm{al}^{47}$ showed that leptin and zinc levels were significantly lower in the group of rats with zinc deficiency, even when compared with the group who had exercised. These results suggest that zinc deficiency exerts a negative influence on leptin levels and that zinc supplementation has the opposite effect. In the present study, there was a significant reduction of the leptin concentrations after both exercise sessions (CT1 and CT2) without significant changes in zinc concentrations.

Casimiro-Lopes et a ${ }^{11}$ observed a significant correlation between leptin and zinc in male subjects. In our study this correlation was observed only in the $\mathrm{CS}$, a finding difficult to interpret.

\section{CONCLUSION}

The results of this study show that, independently of the training order, a single session of concurrent training promoted significant reduction in blood leptin and cortisol. Nevertheless, a correlation between these variables was observed only after CS. There were no significant changes in zinc concentrations after any of the exercise sessions.

\section{REFERENCES}

1. Bell GJ, Syrotuik D, Martin TP, Burnham R, Quinney HA, 2000 Effect of concurrent strength and endurance training on skeletal muscle properties and hormone concentrations in humans. Eur J Appl Physiol 81: 418427.

2. Leveritt M, Abernethy PJ, Barry B, Logan PA, 2003 Concurrent strength and endurance training: the influence of dependent variable selection. J Strength Cond Res 17: 503-508.

3. Kanaley JA, Fenicchia LM, Miller CS, et al, 2001 Resting leptin responses to acute and chronic resistance training in type 2 diabetic men and women. Int J Obes Relat Metab Disord 25: 1474-1480.

4. Landt M, Lawson GM, Helgeson JM, et al, 1997 Prolonged exercise decreases serum leptin concentrations. Metabolism 46: 1109-1112.

5. Keller P, Keller C, Steensberg A, Robinson LE, Pedersen $\mathrm{BK}, 2005$ Leptin gene expression and systemic levels in healthy men: effect of exercise, carbohydrate, interleukin-6, and epinephrine. J Appl Physiol 98: 1805-1812.

6. Jürimäe J, Jürimäe T, 2005 Leptin responses to short term exercise in college level male rowers. Br J Sports Med 39: 6-9.

7. Kraemer WJ, Volek JS, Bush JA, Putukian M, Sebastianelli
WJ, 1998 Hormonal responses to consecutive days of heavy-resistance exercise with or without nutritional supplementation. J Appl Physiol. 85: 1544-1555.

8. Izquierdo M, Ibáñez J, Häkkinen K, Kraemer WJ, Ruesta M, Gorostiaga EM, 2004 Maximal strength and power, muscle mass, endurance and serum hormones in weightlifters and road cyclists. J Sports Sci 22: 465-478.

9. França SC, Barros Neto TL, Aqresta MC, Lotufo RF, Kater CE, 2006 Resposta Divergente da Testosterona e do Cortisol Séricos em Atletas Masculinos Após Uma Corrida de Maratona. Arq Bras Endocrinol 50: 10821087.

10. Izquierdo M, Ibañez J, Calbet JA, et al, 2009 Cytokine and hormone responses to resistance training. Eur J Appl Physiol 107: 397-409.

11. Casimiro-Lopes G, de Oliveira-Junior A, Portella E, et al, 2009 Plasma Leptin, Plasma Zinc, and Plasma Copper Are Associated in Elite Female and Male Judo Athletes. Biol Trace ElemRes 127: 109-115.

12. Fernández-Riejos P, Najib S, Santos-Alvarez J, et al, 2010 Role of Leptin in the Activation of Immune Cells. Mediators of Inflamm 2010 (568343):1-8.

13. Bluher S, Mantzoros C, 2009 Leptin in humans: lessons from translational research. Am J Clin Nutr 89: 991S-997S.

14. Negrão AB, Licinio J, 2000 Leptina: o Diálogo entre Adipócitos e Neurônios Arq Bras Endocrinol Metab 44: 205-214.

15. Rosa G, Cruz L, Mello DBd, Fortes MdSR, Dantas EHM, 2010 Plasma levels of leptin in overweight adults undergoing concurrent training. International Sport Med Journal 11: 356-362.

16. Gómez-García A, Hernández-Salazar E, González-Ortiz M, Martínez-Abundis E, 2006 Efecto de la administración oral de zinc sobre sensibilidad a la insulina y niveles séricos de leptina y andrógenos en hombres con obesidad. Rev Méd Chile 134: 279-284.

17. Baltaci A, Mogulkoc R, Halifeoglu I, 2005 Effects of zinc deficiency and supplementation on plasma leptin levels in rats. Biol Trace Elem Res 104: 41-46.

18. Chen M, Song Y, Lin P, 2000 Zinc may be a mediator of leptin production in humans. Life Sci 66: 2143-2149.

19. Canali ES, 2001 Respostas hormonais ao exercício. Rev paul Educ Fís 15: 141-153.

20. Duclos M, Gouarne C, Bonnemaison D, 2003 Acute and chronic effects of exercise on tissue sensitivity to glucocorticoids. J Appl Physiol 94: 869-875.

21. Konukoglu D, Turhan M, Ercan M, Serin O, 2004 Relationship between plasma leptin and zinc levels and the effect of insulin and oxidative stress on leptin levels in obese diabetic patients. J Nutr Biochem15: 757-760.

22. Kwun I, Cho Y, Lomeda R, Kwon S, Kim Y, Beattie J, 2007 Marginal zinc deficiency in rats decreases leptin expression independently of food intake and corticotrophin-releasing hormone in relation to food intake. Br J Nutr 98: 485-489. 
23. Ott E, Shay N, 2001 Zinc deficiency reduces leptin gene expression and leptin secretion in rat adipocytes. Exp Biol Med 226: 841-846.

24. Mantzoros C, Prasad A, Beck F, et al, 1998 Zinc may regulate serum leptin concentrations in humans. J Am Coll Nutr17: 270-275.

25. Pérusse L, Collier G, Gagnon J, et al, 1997 Acute and chronic effects of exercise on leptin levels in humans. J Appl Physiol 83: 5-10.

26. Cadore EL, Pinto R, Lhullier FL, et al, 2010 Physiological effects of concurrent training in elderly men. Int J Sports Med 31: 689-697.

27. Rosa G, de Mello DB, Biehl C, Dantas E, 2010 Níveis de cortisol em adultos com sobrepeso submetidos a treinamento concorrente. Brazilian Journal of Sports and Exercise Research 1: 11-15.

28. ACSM, 2006 Guidelines for exercise testing and prescreption, Lippincott Williams \& Wilkins.

29. World Medical Association Inc, 2008 Declaration of Helsinki. Ethical principles for medical research involving human subjects. 59th WMA General Assembly, Seoul.

30. Marfell-Jones M, 2006 International standards for anthropometric assessment. ISAK: Potchefsroom, South Africa.

31. Nihiser AJ, Lee SM, Wechsler H, et al, 2009 BMI measurement in schools. Pediatrics 124: Suppl 1: 89-97.

32. Baechle TR, Earle RW, 2000 Essentials of strength training and conditioning: Champaign: human kinetics.

33. Robertson RJ, Goss FL, Dube J, 2004 validation of the adult OMINI scale of perceived exertion for cycle ergometer exercise. Med Sci Sports Exerc 36: 102-108.

34. Sigmound R 2004 Estatística não-paramétrica. São Paulo: McGraw-20 Hill.

35. Rosa G, de Mello DB, Daoud R, Cruz L, Dantas E, 2010 Concentración de leptina en adultos con sobrepeso sujetos a un entrenamiento concurrente. Mot Hum 10: 95-102.

36. Hulver MW, Hourmard JA, 2003 Plasma leptin and exercise: recent findings. Sports Med 33: 473-482.

37. Licinio J, Mantzoros C, Negrão AB, 1997 Human leptin levels are pulsatile and inversely related to pituitaryadrenal function. Nat Med 3: 575-579.

38. Sinha M, Sturis J, Ohannesian J, 1996 Ultradian oscillations of leptin secretion in humans. Biochem Biophys Res Commun 228: 733-738.

39. Rosa G, Abdalla A, Dantas E, de Mello DB, 2010 Efeitos de distintas ordens de execução do treinamento concorrente sobre os níveis de cortisol de adultos fisicamente ativos. Revista Brasileira de Ciências da Saúde 8: 13-18.

40. Horne L, Bell G, Fisher B, Warren S, Janowska-Wieczorek A, 1997 Interaction between cortisol and tumour necrosis factor with concurrent resistance and endurance training. Clin J Sport Med 7: 247-251.

41. Hafner SM, Miettinen H, Karhapää P, Mykkänen L, Laakso M, 1997 Leptin concentrations, sex hormones, and cortisol in nondiabetic men. J Clin Endocrinol Metab 82: 1807-1089.

42. Licinio J, 1998 Longitudinally sampled human plasma leptin and cortisol concentrations are inversely correlated. J Clin Endocrinol Metab 33: 1042.

43. Bornstein SR, Uhlmann K, Haidan A, Ehrhart-Bornstein M, Scherbaum WA, 1997 Evidence for a novel peripheral action of leptin as a metabolic signal to the adrenal gland: leptin inhibits cortisol release directly. Diabetes 46: 1235-1238.

44. Koury JC, Donangelo CM, 2003 Zinco, estresse oxidativo e atividade física. Revista de Nutrição 16: 433-441.

45. Arikan S, Akkus H, Halifeoglu I, Baltaci AK, 2008 Comparison of plasma leptin and zinc levels in elite athletes and sedentary people. Cell Biochem Funct. 26: 655-658.

46. Gökbel H, Baltaci AK, Üçok K, Okudan N, Mo ulkoç $\mathrm{R}, 2005$ Changes in serum leptin levels in strenuous exercise and its relation to zinc deficiency in rats. Biol Trace Elem Res 106: 247-252.

47. Baltaci AK, Ozyurek K, Mogulkoc R, Kurtoglu E, Ozkan Y, Celik I, 2003 Effects of zinc deficiency and supplementation on the glycogen contents of liver and plasma lactate and leptin levels of rats performing acute exercise. Biol Trace Elem Res 96: 227-236. 